\title{
An automatic atmospheric observation system for the stratospheric platform airship
}

\author{
Hiroshi Yoshida ${ }^{1}$, Taro Aoki ${ }^{1}$, Shojiro Ishibashi ${ }^{1}$ and Toshinobu Machida ${ }^{2}$
}

\begin{abstract}
We have developed an automatic atmospheric observation system to measure $\mathrm{CO}_{2}$ levels continuously in the stratosphere for the study of global warming and other environmental problems.

The system consists of two major parts: an automatic atmospheric air sampler and a sequential carbon dioxide $\left(\mathrm{CO}_{2}\right)$ gas level meter equipped with an NDIR analyzer. The system is controlled with a pre-programmed microcomputer and powered by a Liion battery pack. The system runs on a stand-alone mode or a remote control mode. In both modes, the data measured and the system status are monitored from a land station via radio wave. We had carried out stratospheric environment tests and reliability tests. The test results show that the system samples/compresses air into the bottles with pressure of $150 \mathrm{kPa}$ and measures levels of $\mathrm{CO}_{2}$ continuously with precision of about $0.2 \mathrm{ppm}$ in the stratosphere up to $15,000 \mathrm{~m}$.
\end{abstract}

Keywords: Stratospheric platform airship, Green house effect, $\mathrm{CO}_{2}$ gas meter, Gas sampler.

\section{Introduction}

A Stratospheric Platform (SPF) is a large-scale airship which stays a predetermined position at about 20 $\mathrm{km}$ high in the stratosphere. The platform will be used for the environmental measurement, telecommunication, and broadcasting. The project has been promoted since 1998 through the ministerial cooperation of the Ministry of Education, Culture, Sports, Science and Technology and the Ministry of Public Management, Home Affairs, Post and Telecommunications.

A series of airship system design studies and R\&D of airship technologies have been conducted at NAL (National Aerospace Laboratory of Japan) since 1998. They have developed two types of airships: a non-powered airship for the Ground to Stratosphere Flight Test ${ }^{1)}$ and a powered airship for the Low Altitude Stationary Flight Test ${ }^{2}$. In August 2003, the non-powered airship was launched from Hitachi Port in Ibaraki Prefecture to the stratosphere to test the structural design technology of membrane materials and airship hull. The SPF is required not only to reach the stratosphere but also to have the capability of staying afloat geo-stationary. To show this capability, the powered airship system has tested from July to November 2004. An airship hangar and a flight control building were also constructed adjacent to the Multipurpose Aviation Park in Taiki-cho in Hokkaido for the Low Altitude Stationary Flight Test.

JAMSTEC takes charge of the R\&D of an observation system for the environmental measurement in the project. The determination of the quantities of greenhouse gases in the stratosphere was selected as the part of "The Millennium Project," which conceives new ventures, and attempts to resolve problems faced by mankind. The Prime Minister initiated this project in October 1999. Since 2000, we have developed an automatic atmospheric observation system ${ }^{3)}$, 4) (AOS) that measures the quantities of $\mathrm{CO}_{2}$ continuously and samples atmospheric air.

In this report, we introduce the SPF system briefly, and then explain configuration of the AOS in detail. Some test results are given. In conclusion, we discuss the system performance and mention the future some plans.

\section{System configuration}

\subsection{Airship}

The stratospheric platform airship developed in NAL (National Aerospace Laboratory of Japan) is shown in Fig. 1. The airship is of $46 \mathrm{~m}$ long, $12 \mathrm{~m}$ in diameter,

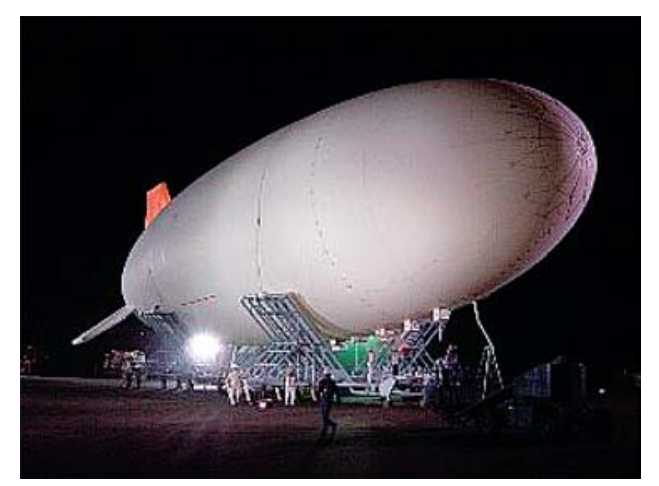

Figure 1: Overview of the airship 
Table 1: Maximum payloads

\begin{tabular}{|c|c|}
\hline Items & Payload \\
\hline Dimension & $\begin{array}{c}450 \times 450 \times 450 \mathrm{~mm} \times 2 \\
\text { packs }\end{array}$ \\
\hline Weight & $40 \mathrm{~kg}$ \\
\hline Interface & RS-232C compatible \\
\hline
\end{tabular}

and $500 \mathrm{~kg}$ in weight. The non-rigid airship has helium gas and air within its body. The non-powered airship floats into stratosphere with the payload of about $40 \mathrm{~kg}$ in weight. The flight plan of the airship is the followings: 1-hour ascent, 30 minutes level flight, and $30 \mathrm{~min}$ utes descent. The airship can be controlled from a land station and an offshore station via radio communication. Table 1 shows the maximum payload and interface of the airship

\subsection{The automatic atmospheric observation sys- tem (AOS)}

The system has two functions: the continuous determination of the quantities of carbon dioxide and the discrete sampling of atmospheric air into two bottles. The air sampled is analyzed its components at the laboratory that has technology and facilities for sophisticated gas analysis after retrieving the system. The quantities of carbon dioxide and the other greenhouse gases, such as methane $\left(\mathrm{CH}_{4}\right)$, and nitrous oxide $\left(\mathrm{N}_{2} \mathrm{O}\right)$ are identified by the analysis.

\subsection{System configuration}

The AOS runs on a stand-alone mode or a remote control mode. In the both modes, the obtained data and the system status are monitored from a land station via radio wave except for beginning and ending of the observation mission. To begin/end the mission the system receives a start/stop-command from the land station via the airship control system.

The system requirement is shown in Table 2. Figures 2 and 3 show an appearance of the AOS and the system block-diagram, respectively. The AOS system consists of two major parts; the observation part that provides the two functions as mentioned above and the control part that controls and powers to the former. Each part is housed in the aluminum cabinet of cube $45 \mathrm{~cm}$ on a side. The one cabinet is connected through the electrical wiring harness to the other one. Each cabinet is packed in the bag made from Vectran woven cloth, which is used for the airship hull.

In the last stage of the Ground to Stratosphere Flight Test, the airship hull is bombed-out and then airship crash on sea surface. We, therefore, never get a second
Table 2: Specifications of the system

\begin{tabular}{|c|c|}
\hline Item & Specification \\
\hline The sequential $\mathrm{CO}_{2}$ level meter & \\
Dynamic range & $340 \sim 400 \mathrm{ppm}$ \\
Accuracy & $\pm 0.2 \mathrm{ppm}$ \\
Interval & $1 \mathrm{~s}$ \\
\hline The air sampler & 2 \\
Number of sampling bottle & Stainless steel \\
Material of bottles & $300 \mathrm{cc}$ \\
Capacity & $150 \mathrm{kPa}$ \\
Maximum sampling pressure & \\
\hline The controller and power supply & DC28V (Li-ion battery) \\
Battery voltage & 2.5 hours \\
Endurance & Flash memory \\
Memory & RS232C \\
Interface &
\end{tabular}

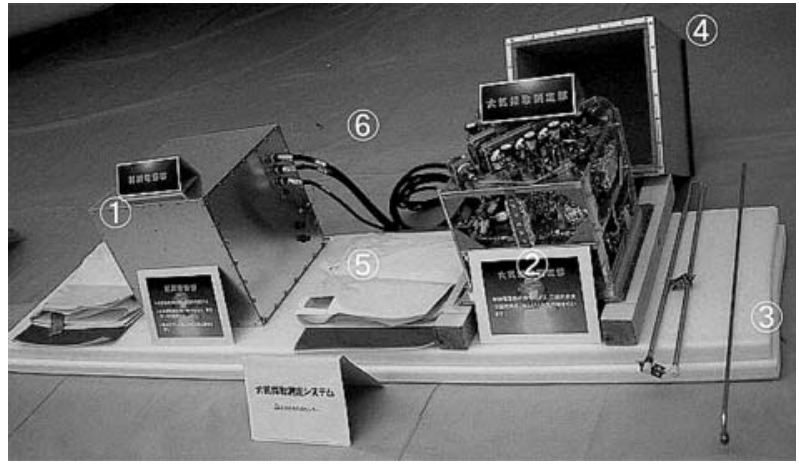

Figure 2: An appearance of the AOS. (1) the control part, (2) the observation part, (3) the nozzle for leading gas to the observation part, (4) the cabinet, (5) the bag, (6) the electrical wiring harness.

chance to measure gasses in the stratosphere with the AOS. The AOS is adopted redundant design to avoid the system error in the Test.

\subsubsection{The observation part}

The part consists of two pumps, filters, valves, a gassampler, and a $\mathrm{CO}_{2}$ gas meter. Figure 4 shows the observation part assembled. The two diaphragm pumps are connected in series to pump gas up to $10 \mathrm{kPa}$. One of the valves switches the incoming airflow to the sampler and the gas meter. The gas-sampler consists of two stainless bottles of which capacity is $300 \mathrm{cc}$, two pressure gages, and valves. The two bottles, of which insides are electropolished, are used for air sampling at different altitudes. One of the gages determines the pressure at the inlet of the bottle. The other one is at the outlet. The gas meter consists of two voltage controlled variable valves, a mass flow meter, a pressure gage, an NDIR (Non-dispersive infrared) $\mathrm{CO}_{2}$ analyzer, and two 


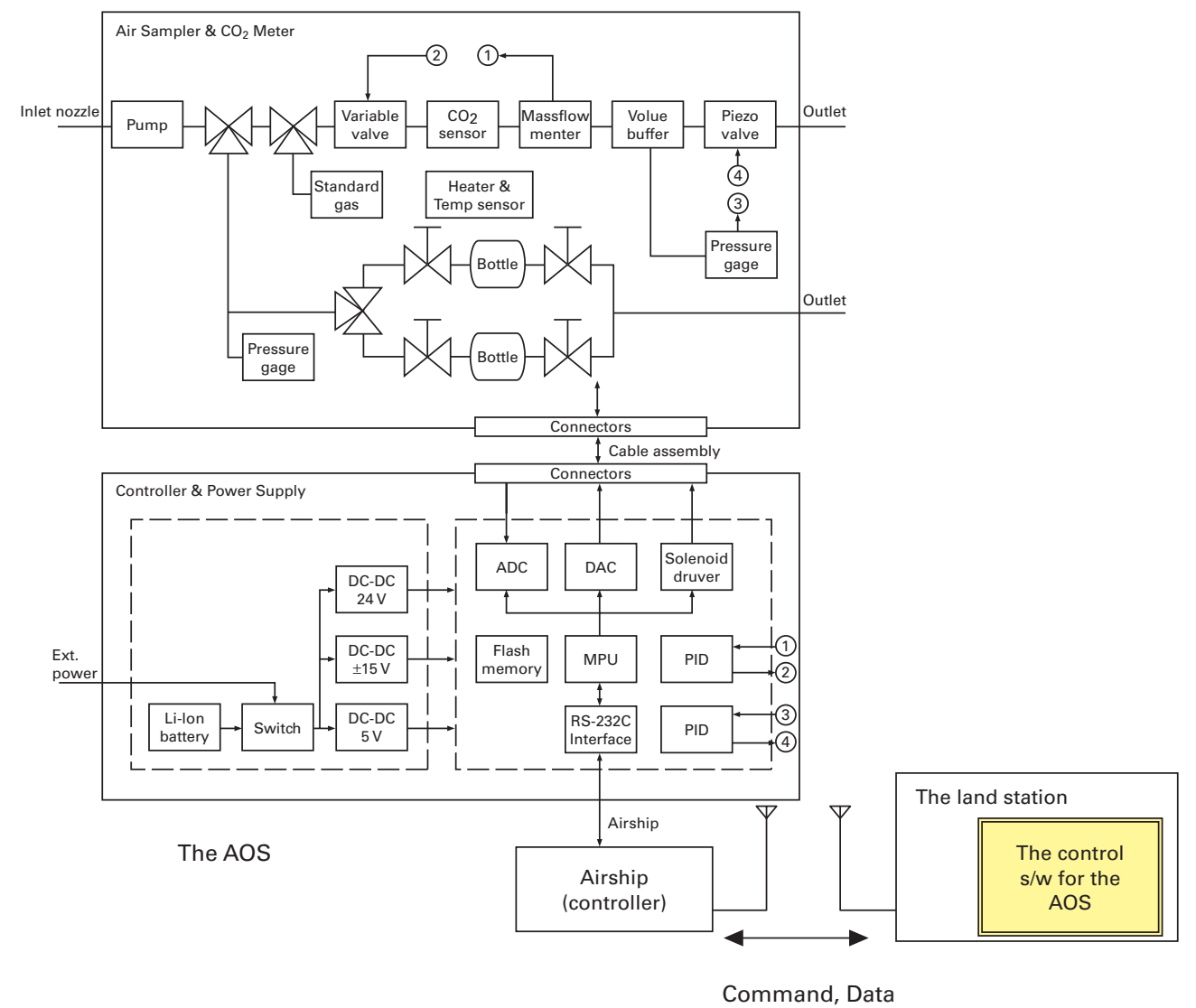

Figure 3: Blockdiagram of the AOS.

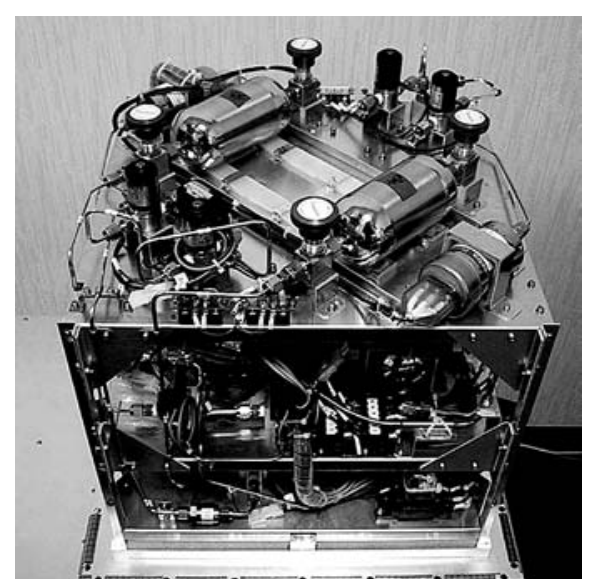

Figure 4: The observation part. Lower: the gas analyzer and Upper: the sampler.

standard gas bottles. One of the valves is controlled with a mass flow PID controller. The flow is set to the specified flow of the analyzer. The other valve varies with output voltage of the pressure PID to keep suitable pressure for the analyzer. The $\mathrm{CO}_{2}$ analyzer ${ }^{5)}$ is a low cost, low maintenance one designed for continuous monitoring applications, and the analyzer used here is based on a single path, dual wavelength, and infrared detection system. The original precision of the analyzer is about
$4 \mathrm{ppm}$. To improve the precision, the analyzer refers the two calibrated standard gases filled in the bottles. The calibrated $\mathrm{CO}_{2}$ gases of $340 \mathrm{ppm}$ and $370 \mathrm{ppm}$ were used. In the unit, the measurement of atmospheric $\mathrm{CO}_{2}$ and the two calibrated gases are alternated with a period of 12 minutes. The sampling speed of the analyzer is 1 sample-per-second. The measured data is low-pass filtered and averaged over 10 seconds to decrease the internal noise ( $4 \mathrm{ppm})$ of the analyzer.

\subsubsection{The control part}

The control part consists of a system controller and a power supply as shown in Figures 5 (a) and (b), respectively. The controller controls the observation part, communicates with the airship, and memorizes the software execution trace, the system status and the $\mathrm{CO}_{2}$ gas level in SRAMs and flush memories. The power supply consists of Li-ion batteries (29.6 V typical, 21.6Ah) and input-output isolated DC-DC converters. The internal latching relay of the power supply is activated when an external power is supplied. Once the system power turns on, the system runs without the external power. The system endurance is about 3 hours considering the performance degradation of the batteries in lower temperature. 

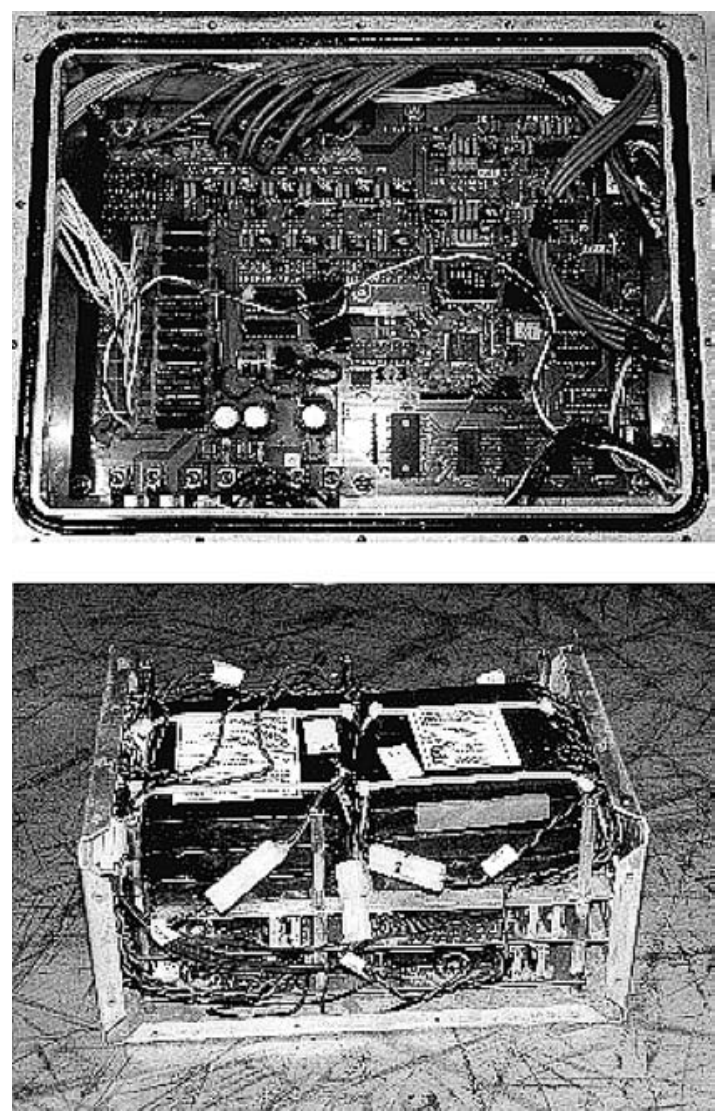

Figure 5: The control part. (a) The controller installed into the water resistant hull. (b) The power supply; upper: Li-ion batteries, lower: Power Controller.

To radiate the heat at the DC-DC converters, the converter is connected with the aluminum cabinet via the heat direction plate, which is optimized its size and thickness. The system works properly from the ground to the stratosphere by use of the plate.

\subsubsection{The gas inlet}

To avoid contamination caused by the emission from surface of the airship envelope, the stainless pipe of one meter is equipped as an inlet. The sampling port orients to the traveling direction of the ship

\subsection{The system operation}

The AOS is powered on by connecting an external power supply. The measuring sequence of AOS is started by "START" command from the land station via the airship. The system is shut down by "SHUT DOWN" command.

After starting the sequence, the system receives the altitude data from the airship every 1 second. The system alternatively makes the continuous $\mathrm{CO}_{2}$ measurement and the air sampling according to the preprogrammed target altimeter. In the $\mathrm{CO}_{2}$ measurement, the

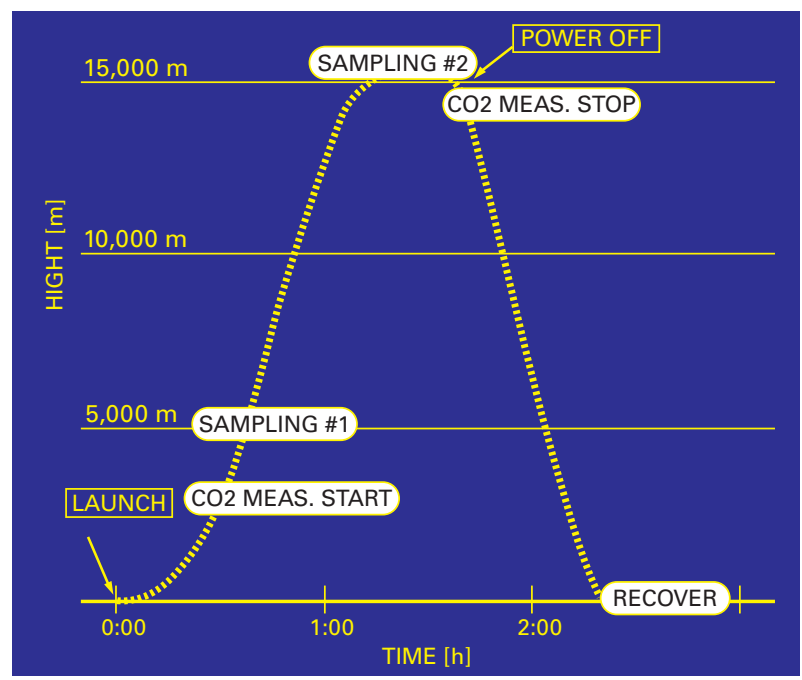

Figure 6: The operation sequence of the AOS.

AOS works periodically. In one period of $12 \mathrm{~min}$, the NDIR analyzer measures the lower calibrated gas and the higher calibrated gas for 1 minute each, then measuring the atmosphere taking from the inlet for $10 \mathrm{~min}$ utes. Before gas sampling, the bottles are purged with intake gas for the preprogrammed period. Finishing the purge, the intake gas is compressed in the bottles up to the pressure of $150 \mathrm{kPa}$.

Figure 6 shows the operation sequence of the AOS in the Ground to Stratosphere Flight Test. In the test, The "START" command is sent just before launching the airship. The $\mathrm{CO}_{2}$ measurement is started at about $3,000 \mathrm{~m}$. The samplings are done at about 5,000 $\mathrm{m}$ and $15,000 \mathrm{~m}$.

If the altitude data is not received after starting the sequence, the measurement and the samplings are automatically started with an internal timer.

\section{Test}

\subsection{Test for electrical characteristics}

\subsubsection{The air sampler}

The pumps of the AOS pump the intake air of $10 \mathrm{kPa}$ to the pressure of $150 \mathrm{kPa}$ in a test chamber. Figure 7 shows a time-of-flight oscillogram of sampling pressure to the bottle under pseudo environment of the stratosphere around $15,000 \mathrm{~m}$. The bottle is purged with sampling air for 15 minute, and then its outlet valve is closed to fill the bottle with the air. In the figure, the pressure in the bottle is over $150 \mathrm{kPa}$ in the latest oneminute period.

\subsubsection{The sequential $\mathrm{CO}_{2}$ gas meter}

In order to test the system, we prepared a test chamber that can simulate the environment of the strato- 


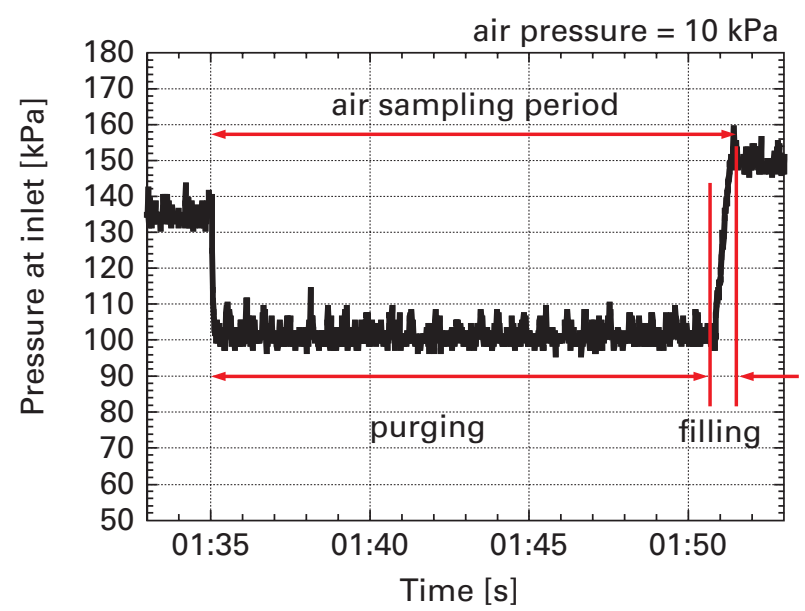

Figure 7: A typical oscillogram of pressure at inlet of the sampling bottle.

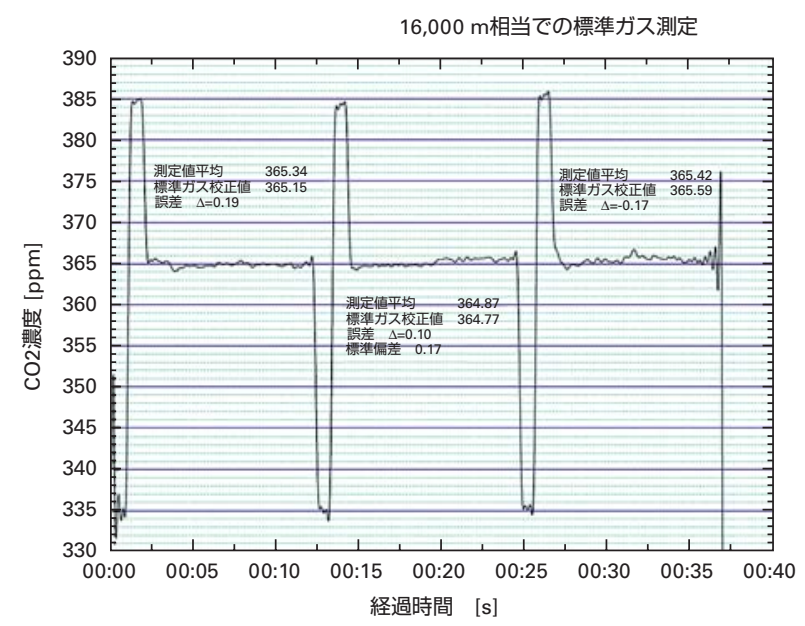

Figure 8: The $\mathrm{CO}_{2}$ level measured in the test chamber.

sphere. Figure 8 shows a $\mathrm{CO}_{2}$ gas level measured in the test. A calibrated standard $\mathrm{CO}_{2}$ gas is directed into the system. The measured level of the $\mathrm{CO}_{2}$ gas analyzer is filtered and averaged for 10 seconds to eliminate the internal noise of the analyzer. The standard deviation of the obtained level is 0.17 for the one measured period. We compared the known $\mathrm{CO}_{2}$ level of the standard gas with the measured one. As a result, we obtained the maximum error of the measured $\mathrm{CO}_{2}$ level of $0.19 \mathrm{ppm}$. These level are met the target specifications.

\subsection{Environmental test to confirm the reliability of the system}

We made the environmental tests as the followings: a constant-temperature and constant-pressure test, a forced vibration test, electromagnetic immunity (EMI) and electromagnetic compatibility (EMC) tests, a temperature rise test, drop test, and a heat cycle test.

In the constant-temperature and constant-pressure
Table 3: The $\mathrm{CO}_{2}$ level analyzed in the gas bottle.

\begin{tabular}{|c|c|c|}
\hline & Altitude & $\mathrm{CO}_{2}$ level \\
\hline$\# 1$ & $5000 \mathrm{~m}$ & $375.1 \mathrm{ppm}$ \\
\hline$\# 2$ & $7000 \mathrm{~m}$ & $375.3 \mathrm{ppm}$ \\
\hline
\end{tabular}

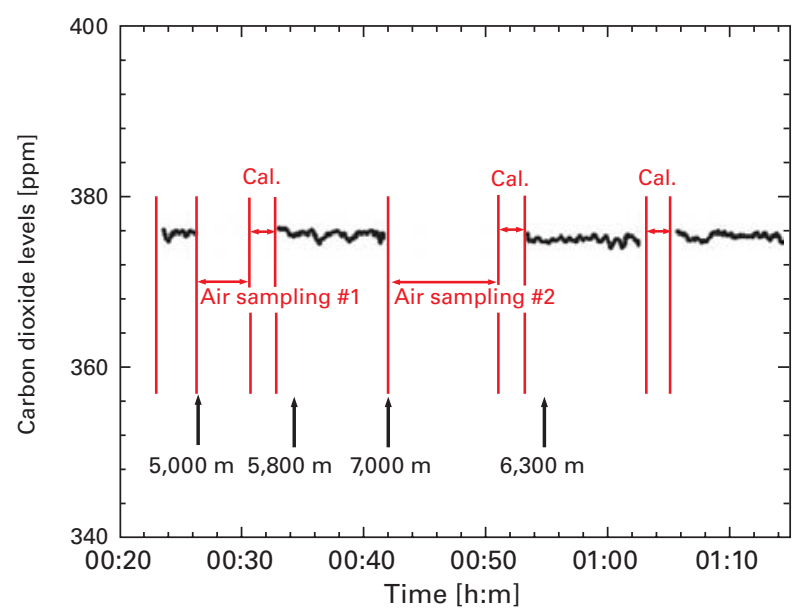

Figure 9: The $\mathrm{CO}_{2}$ level measured.

test, we made system adjustments and performance evaluations at around 15,000 $\mathrm{m}$ by use of the MZH-11H test chamber produced by Espec. Flight simulate tests were also done in this test. In the vibration test, a vibrator applies shock to the system in three different directions. In the EMI and EMC tests, the system was modified to meet the DO-160 standards.

\subsection{Air flight test}

The air flight test was done with the airplane, "Beach Craft" of NAL on January 17, 2004, to avoid failure due to nonpredictable factor that does not emerge in the environmental test. The flight altitude was up to 7,000 $\mathrm{m}$ and area was over Hatsushima-Island. The system worked as required.

Table 3 shows the result of analysis of the gas sampled. Figure 9 shows the $\mathrm{CO}_{2}$ level measured. Both results are not obtained in same time, because the system alternates the $\mathrm{CO}_{2}$ measuring and the air sampling. Therefore, the both results cannot be compared directly. To make a rough agreement in the both for crosscheck, we average the $\mathrm{CO}_{2}$ level measured just before (about 7,000 $\mathrm{m}$ in Fig. 9) and after (about 6,300 m) the \#2 gas sampling. The averaged level is nearly equal to of the gas obtained in the \#2 gas sampling.

\subsection{The Ground to Stratosphere Flight Test}

On August 4, 2004, the flight test of the stratospheric platform airship was carried out at Hitachi-port. The AOS could not start observation, unfortunately, because 
the system did not receive the observation start signal from the land station with unidentified failure. It is necessary to improve reliability of the AOS including the airship for the next step R \& D of the stratospheric platform system.

\section{Concluding Remarks}

We introduce the specifications, the system operation, and the some test results of the AOS on the non-powered airship. The discussions for the test results are given. The AOS system is found to meet its specification. The AOS works properly in the environmental test and the air-flight test.

We found that the NDIR $\mathrm{CO}_{2}$ analyzer modified can work in the stratosphere. The analyzer output is slightly changed with time. This phenomenon has little impact on short time measurement such as two hours observation, but affects the long time measurement. We must eliminate this problem when the practical model of the AOS will be developed.

In this system architecture, some calibrated gases must be needed. If a practical type airship will have large payload such as $200 \mathrm{~kg}$ or more, the airship can carry much calibrated gases. If no, we need to develop another architecture.
The system could not test on the non-powered airship in the stratosphere. For the next step stratospheric platform system, a smaller, lighter and power-saving observation system should be developed. It is necessary to research other greenhouse gas measuring system in the near future.

\section{References}

1) Shuichi Sasa, Kazuo Ohashi, Hiroshi Yoshida, Takao Miyazaki, "Ground to Stratosphere Flight Test", Proc. The 35th TJSASS, 2004.

2) Masaaki Nakadate, "Flight Test Overview of Low Altitude Stationary Flight Test Vehicle", Proc. The Fifth Stratospheric Platform Systems Workshop (2005).

3) Hiroshi Yoshida, Yutaka Kaneko, The status and the future plan of the R \& D of the SPF earth observation system, Proc. The forth Stratospheric Platform Systems Workshop, pp.40-50, Feb. 26-27, 2003.

4) Hiroshi Yoshida, Taro Aoki, Shojiro Ishibashi, Toshinobu Machida, Tadahiro Hyakudome, "A stratospheric platform airship-installed atmospheric observation system," Proc. The Fifth Stratospheric Platform Systems Workshop, 2005.

5) LI-COR, "LI-800 datasheet." 